\title{
Dysregulation of the Wnt pathway inhibits timely myelination and remyelination in the mammalian CNS
}

\author{
Stephen P.J. Fancy, ${ }^{1,2}$ Sergio E. Baranzini, ${ }^{3}$ Chao Zhao, ${ }^{2}$ Dong-In Yuk, ${ }^{4}$ Karen-Amanda Irvine, ${ }^{5}$ \\ Sovann Kaing, ${ }^{1}$ Nader Sanai, ${ }^{5}$ Robin J.M. Franklin, ${ }^{2,8}$ and David H. Rowitch ${ }^{1,5,6,7}$ \\ ${ }^{1}$ Institute for Regeneration Medicine and Howard Hughes Medical Institute, University of California at San Francisco, San \\ Francisco, California 94143, USA; ${ }^{2}$ MRC Centre for Stem Cell Biology and Regenerative Medicine and Department of Veterinary \\ Medicine, University of Cambridge, Cambridge CB3 OES, United Kingdom; ${ }^{3}$ Department of Neurology, University of California \\ at San Francisco, San Francisco, California 94143, USA; ${ }^{4}$ Department of Pediatric Oncology, Dana-Farber Cancer Institute, \\ Boston, Massachusetts 02115, USA; ${ }^{5}$ Department of Neurosurgery, University of California at San Francisco, San Francisco, \\ California 94143, USA; ${ }^{6}$ Department of Pediatrics, University of California at San Francisco, San Francisco, California 94143, \\ USA
}

The progressive loss of CNS myelin in patients with multiple sclerosis (MS) has been proposed to result from the combined effects of damage to oligodendrocytes and failure of remyelination. A common feature of demyelinated lesions is the presence of oligodendrocyte precursors (OLPs) blocked at a premyelinating stage. However, the mechanistic basis for inhibition of myelin repair is incompletely understood. To identify novel regulators of OLP differentiation, potentially dysregulated during repair, we performed a genome-wide screen of 1040 transcription factor-encoding genes expressed in remyelinating rodent lesions. We report that $\sim 50$ transcription factor-encoding genes show dynamic expression during repair and that expression of the Wnt pathway mediator Tcf4 (aka Tcf712) within OLPs is specific to lesioned-but not normal-adult white matter. We report that $\beta$-catenin signaling is active during oligodendrocyte development and remyelination in vivo. Moreover, we observed similar regulation of Tcf4 in the developing human CNS and lesions of MS. Data mining revealed elevated levels of Wnt pathway mRNA transcripts and proteins within MS lesions, indicating activation of the pathway in this pathological context. We show that dysregulation of Wnt- $\beta$-catenin signaling in OLPs results in profound delay of both developmental myelination and remyelination, based on (1) conditional activation of $\beta$-catenin in the oligodendrocyte lineage in vivo and (2) findings from $A P C^{M i n}$ mice, which lack one functional copy of the endogenous Wnt pathway inhibitor APC. Together, our findings indicate that dysregulated Wnt- $\beta$-catenin signaling inhibits myelination/remyelination in the mammalian CNS. Evidence of Wnt pathway activity in human MS lesions suggests that its dysregulation might contribute to inefficient myelin repair in human neurological disorders.

[Keywords: Oligodendrocyte; CNS development; Wnt; multiple sclerosis; remyelination; Olig2]

Supplemental material is available at http://www.genesdev.org.

Received March 30, 2009; revised version accepted May 19, 2009.

The oligodendrocyte is the myelinating cell of the CNS (Miller 2002). In multiple sclerosis (MS), a common cause of neurological disability in young adults, the myelin sheaths are lost through the injury or death of mature oligodendrocytes (Compston and Coles 2008). Myelin sheaths can be restored by oligodendrocytes newly generated following the recruitment and differentiation of oligodendrocyte precursor (OLP) cells. This event, called

Corresponding authors.

${ }^{7}$ E-MAIL rowitchd@peds.ucsf.edu; FAX (415) 476-9976.

${ }^{8}$ E-MAIL rjf1000@cam.ac.uk; FAX 44-1223-337610.

Article published online ahead of print. Article and publication date are online at http://www.genesdev.org/cgi/doi/10.1101/gad.1806309. Freely available online through the Genes \& Development Open Access option. "remyelination," is normally one of the most efficacious regenerative processes in neurobiology. However, although it can be extensive in MS (Patrikios et al. 2006; Patani et al. 2007), it is an inconsistent event, and the accumulated load of lesions that fail to remyelinate in a timely manner contributes to irreversible axon loss and progressive neurological deterioration (Frohman et al. 2006; Trapp and Nave 2008).

The finding of OLPs and premyelinating oligodendrocytes in chronic lesions of MS suggests that remyelination is most vulnerable during the differentiation rather than the recruitment phase (Wolswijk 1998; Chang et al. 2002; Kuhlmann et al. 2008). One possible explanation is the persistent expression of differentiation inhibitors in 
chronic lesions. Several such differentiation inhibitors have been suggested to have roles including the Notch pathway (John et al. 2002), PSA-NCAM (Charles et al. 2002), hyaluronan (Back et al. 2005), and LINGO-1 (Mi et al. 2005).

Important insights into the cell-intrinsic mechanisms that regulate OLPs during remyelination have come from genetic analysis of transcription factor (TF)-encoding genes. For example, Olig1 function is critical for repair of demyelinated lesions in the adult CNS (Arnett et al. 2004) in that it promotes differentiation from OLP to mature remyelinating oligodendrocyte. More recently, repression of putative differentiation inhibitory TFs by histone deacetylation has also been implicated in enabling OLP differentiation into remyelinating oligodendrocytes (Shen et al. 2008). TFs as a class also have utility as nuclear markers (easy to distinguish from adjacent cells) in translational studies of human pathobiology (Arnett et al. 2004; Ligon et al. 2004; Kuhlmann et al. 2008).

To further define molecular regulation of remyelination and identify potential therapeutic targets, we used a whole-genome in situ expression screen to identify TF-encoding genes using a toxin-induced experimental model of demyelination in which remyelination proceeds in a stereotypic and well-characterized sequence of OLP recruitment and differentiation. We report that $>50 \mathrm{TF}-$ encoding genes show up-regulation during key stages of repair in various cells within white matter lesions. Among factors identified in oligodendrocytes, we focused on Tcf4 because its expression was specific to damaged white matter in the adult CNS. Moreover, expression profiling confirmed Wnt pathway gene expression during remyelination. Based on this, we show detailed analysis of the activation of the canonical Wnt pathway and its intranuclear mediator, Tcf4, during oligodendrocyte development and in demyelinated lesions in the mouse and human CNS, as well as a conserved pattern of expression in human MS lesions. We provide functional data to show that activated Tcf4-catenin signaling can act as a profound negative regulator of oligodendrocyte differentiation during myelination and remyelination. Together, our findings lead to the proposal that dysregulation of the canonical Wnt pathway contributes to failure of effective myelin repair. Furthermore, they provide a framework to understand complex molecular regulation of remyelination by TFs in CNS development and demyelinating disease.

\section{Results}

Whole-genome screen for TFs expressed during remyelination

We performed a de novo whole-genome in situ expression-based screen using a unique library of 1040 probes for TF-encoding genes (Gray et al. 2004). We injected lysolecithin into ventrolateral white matter of adult mouse spinal cord (Arnett et al. 2004) and harvested lesions for analysis at 5, 10, and $14 \mathrm{~d}$ post-lesion (dpl), corresponding to the timing of peak OLP recruitment, initiation of OLP differentiation, and myelin sheath formation, respectively. Of 1040 probes screened on tissue arrays of remyelinating lesions at multiple stages (Fig. 1A), a primary screen revealed $\sim 50$ genes showing altered expression within lesions at some or all of these key stages of myelin repair (Supplemental Table 1). For example, as shown in Figure 1B, Thyroid hormone receptor $\alpha$ (Thra), which encodes a receptor for thyroid hormone, a known factor associated with OLP differentiation (Barres et al. 1994), showed dynamic expression with a sharp peak at $10 \mathrm{dpl}$ when OLP differentiation commences in this lesion model. In contrast, Spi2.2 expression commenced at $5 \mathrm{dpl}$ and was maintained in the lesion thereafter. Based on these findings, one might postulate temporally distinct functions.

To further characterize expression of these factors, in order to assemble putative TF regulatory patterns within lesions, further screening of our $\sim 50$ candidate genes (Supplemental Table 1) is ongoing. A secondary screen identifies the cell type specificity of expression of these factors within remyelinating lesions using double in situ hybridization-immunohistochemistry (ISH-IHC) labeling. Finally, to account for possible regionally restricted repair roles of TFs in the anterior-posterior axis, we confirm expression in multiple models of remyelination including (1) focal lesions of mouse spinal cord-lysolecithin injection, (2) focal lesions of rat cerebellar peduncle-ethidium bromide (EtBr) injection, and (3) diffuse lesions of mouse corpus callosum cuprizone ingestion (Blakemore and Franklin 2008). We did not use an experimental autoimmune encephalitis (EAE) model in our screen because it is not suitable for precisely measuring repair kinetics after white matter injury.

Examples of factors expressed exclusively in Olig2positive cells during remyelination in the spinal cord include Spi2.2 (Fig. 1C) and COPS3 (Fig. 1D), which also showed similar expression patterns during remyelination of mouse corpus callosum. Because we showed previously that Olig2 cells in these lesions exclusively express other markers of the oligodendrocyte lineage (e.g., Nkx2.2 and PDGFR $\alpha$ ) and not the astrocyte marker GFAP (Arnett et al. 2004), we conclude that Olig2 expression is indicative of the oligodendrocyte lineage. Other TF-encoding genes, including $M a f B$, were expressed in nonoligodendrocyte lineage cells (Fig. 1E). Together, these preliminary findings suggest complex interactions between TFs during regulation of remyelination and provide a basis for further investigation.

\section{Tcf4 expression is specific to remyelinating white matter in the adult CNS}

Among the TFs expressed exclusively by Olig2 ${ }^{+}$cells, we focused on Tcf4 (Tcf712; hereafter called Tcf4) (van de Wetering et al. 2002) because its expression was specific to remyelinating lesions generated by (1) lysolecithininduced demyelination of mouse spinal cord, (2) cuprizoneinduced demyelination of mouse corpus callosum, and (3) EtBr-induced demyelination of rat caudal cerebellar peduncle (CCP) (Fig. 2A; Supplemental Fig. 1), and undetectable at the mRNA or protein level in normal adult white 
A

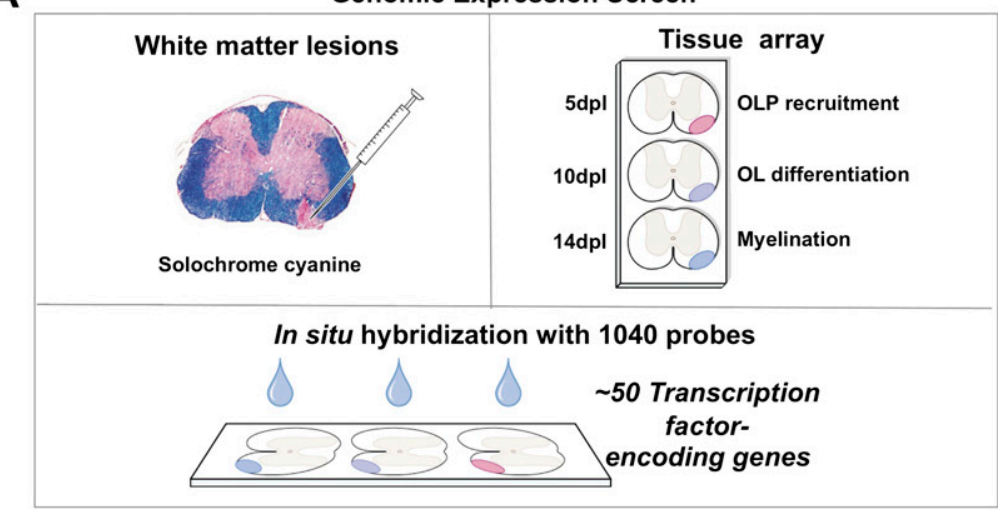

B

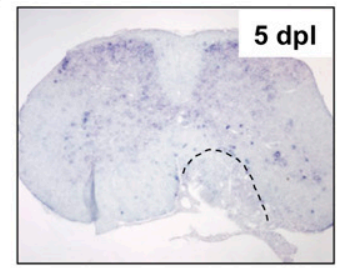

C

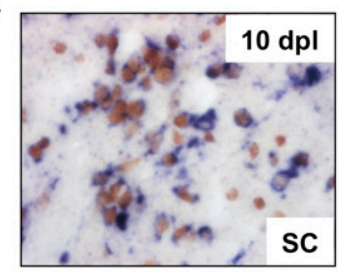

D

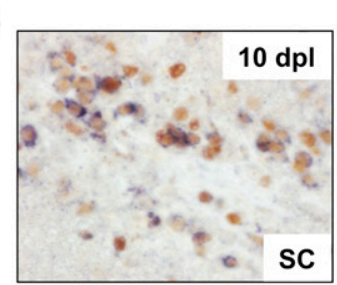

E

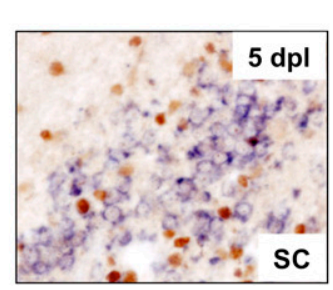

Thro

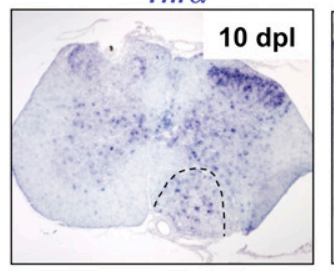

Spi2.2 Olig2

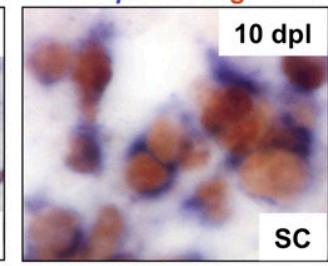

COPS3 Olig 2

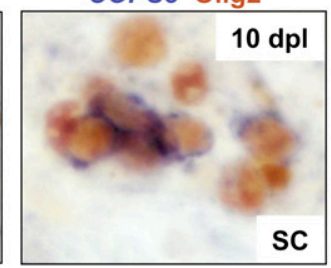

MafB Olig2

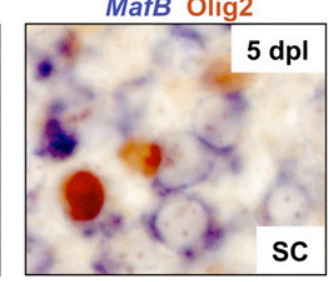

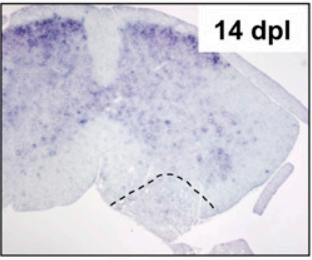

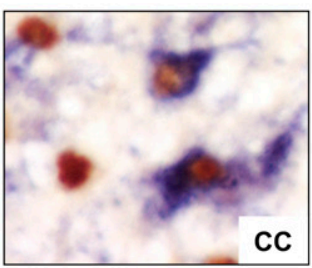

CC

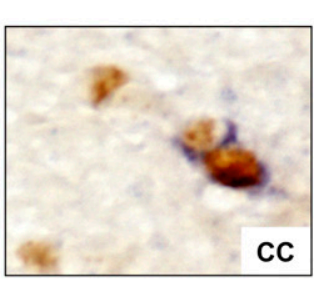

cc

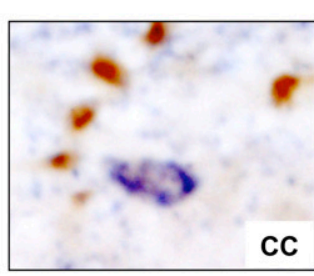

Figure 1. Whole-genome screen for TFs dynamically expressed during remyelination. (A) Diagram illustrating strategy for whole-genome in situ expression-based screen for TF-encoding genes induced during remyelination in adult CNS. $(B)$ Thra, encoding a receptor for thyroid hormone and known factor associated with OLP differentiation, is an example of a factor showing dynamic expression with a sharp peak at $10 \mathrm{dpl}$ when OLP differentiation commences in this lesion model. $(C, D)$ Examples of factors expressed exclusively in Olig2-positive oligodendrocyte lineage cells during remyelination in the spinal cord (SC) include Spi2.2 $(C)$ and COPS3 $(D)$, which also showed similar expression patterns during remyelination of mouse corpus callosum (CC). (E) Other examples including $M a f B$ were expressed in nonoligodendrocyte lineage cells.

matter. In addition, expression profiling of mouse lysolecithin lesions indicated significantly altered Wnt pathway gene expression, including both positive (catenin, Frz1, Frz2, Frz4, Frz7, GSK3 $\beta$, Tcf4, Wnt5a, and Wnt9a) and negative (Apc, Dkk2, Dkk3, and Sfrp4) regulators of the pathway (Supplemental Fig. 2), as expected because many genes encoding Wnt inhibitors are well-established pathway targets (Nelson and Nusse 2004).

Tcf proteins are nuclear binding partners of $\beta$-catenin that mediate transcriptional regulation of Wnt- $\beta$-catenin pathway target genes (Nelson and Nusse 2004). As shown in Figure 2B, Tcf4 protein was first detected during development in white matter of the postnatal day 1 (P1) spinal cord. We did not detect Tcf4 in normal adult white matter but found it was re-expressed following demyelination (Fig. 2B). In this context, Tcf4 expression identified a subset $(23 \%$, SEM 2.5) of Olig2-positive cells at $5 \mathrm{dpl}$, when OLPs are the only oligodendrocyte lineage cells within the lesion (Arnett et al. 2004). This finding was consistent with either Tcf4 expression demarcating an OLP subpopulation responding to demyelination or might reflect asynchronous, stage-restricted expression of Tcf4 in all OLPs during development and remyelination, addressed further below. At $10 \mathrm{dpl}$ and $14 \mathrm{dpl}$, 21\% SEM 


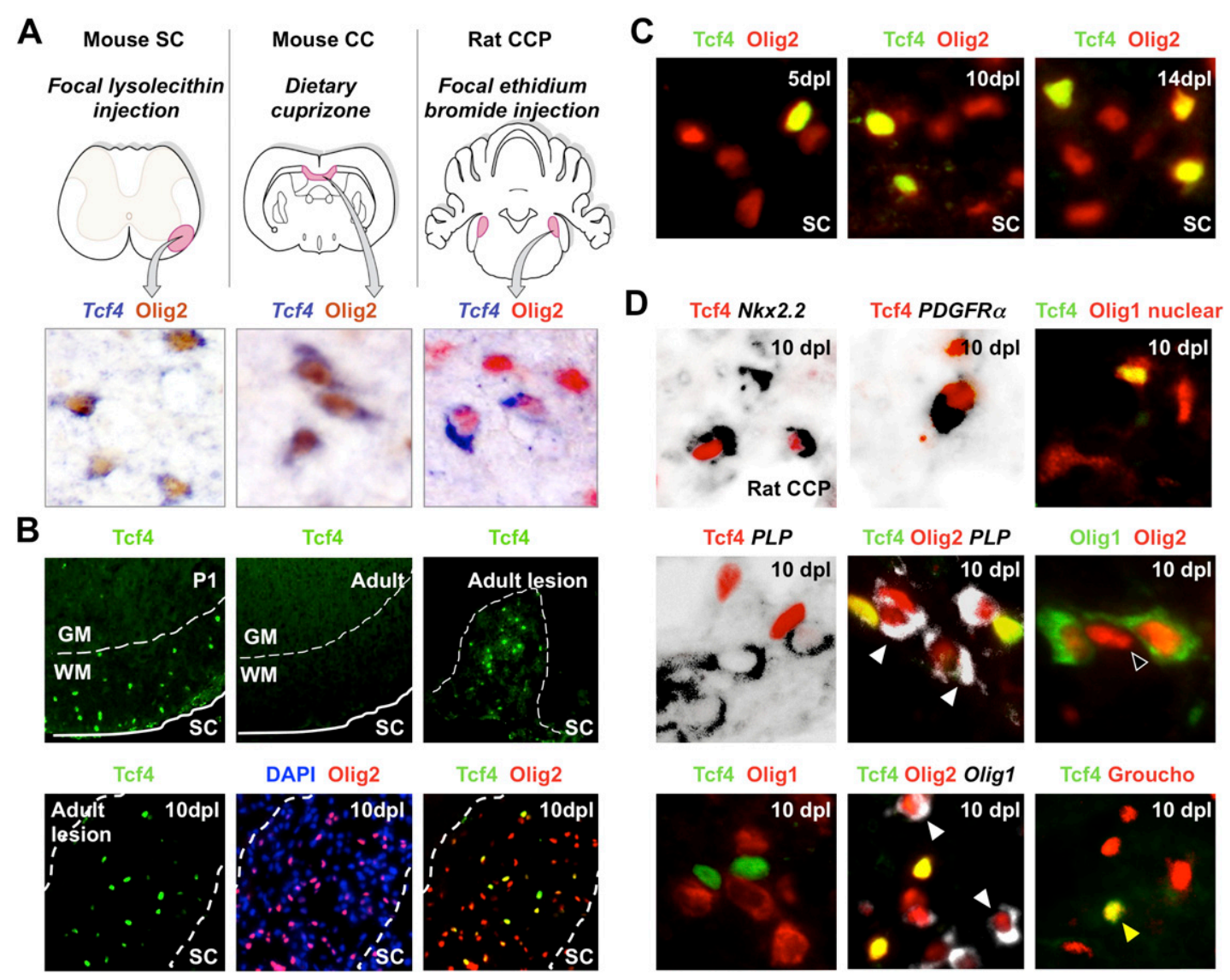

Figure 2. Tcf4 (Tcf712) is expressed in oligodendrocyte lineage during remyelination of adult brain and spinal cord. (A) Expression of Tcf4 (Tcf712) transcripts in three models of CNS remyelination induced by lysolecithin injection in mouse spinal cord (SC), dietary cuprizone in mouse corpus callosum (CC), and EtBr injection in rat CCP. (B) Tcf4 protein is expressed in white matter (WM) of SC during developmental myelination beginning at $\mathrm{P} 1$ and during remyelination of focal demyelination in adult, but is not expressed in the white matter of normal unlesioned adult SC. Low-power whole lesion images are shown of Tcf4 with Olig2 and DAPI/Olig2 during remyelination in the adult. $(C)$ Tcf4 protein is expressed in a subset of Olig2-positive cells within remyelinating areas of lysolecithininduced demyelination in adult mouse SC, at $5 \mathrm{dpl}, 10 \mathrm{dpl}$, and $14 \mathrm{dpl}$. (D) Tcf4 protein expression was confirmed at $10 \mathrm{dpl}$ in EtBrinduced demyelination in adult rat CCP. At $10 \mathrm{dpl}$ in this model, Tcf4 was coexpressed in cells that expressed Nkx2.2 message, PDGFR $\alpha$ message, and nuclear Olig1 protein (which we demonstrated previously identifies OLPs) (Kitada and Rowitch 2006), but Tcf4 expression identified Olig2 cells that segregated from expression of the mature oligodendrocyte marker PLP-exon $3 b$, as well as cytoplasmic Olig1 protein (which we showed previously identifies mature oligodendrocytes) (Arnett et al. 2004; Kitada and Rowitch 2006). Tcf4 colabels a subset of Tle1 (Groucho)-expressing cells in 10-dpl CCP (yellow arrowhead).

3.5 and $19.5 \%$ SEM 2 of Olig2-positive cells coexpressed Tcf4, respectively (Fig. 2C). We confirmed these findings using the rat CCP EtBr model of demyelination (Fig. 2D). At $10 \mathrm{dpl}$ in this model, Tcf4 was coexpressed in cells that expressed Nkx2.2, PDGFR $\alpha$, and nuclear Olig1 protein, which we demonstrated previously identifies OLPs (Arnett et al. 2004; Kitada and Rowitch 2006). However, Tcf4 was not expressed in cells expressing the mature oligodendrocyte marker PLP-exon $3 b$ or that expressed cytoplasmic Olig1 protein, which we showed previously identifies mature oligodendrocytes (Fig. 2D; Arnett et al. 2004; Kitada and Rotwitch 2006). A similar pattern of Tcf4 expression during oligodendrocyte lineage progression was seen during developmental myelination (Fig. 3): Tcf4 labeled only those Olig2 cells (Fig. 3A) that expressed PDGFR $\alpha$ (Fig. 3D) and nuclear Olig1 protein (Fig. 3B) but not those expressing PLP-exon 3b (Fig. 3D) and cytoplas- mic Olig1 protein (Fig. 3C). Together, these findings suggested that canonical Wnt signaling might regulate differentiation of OLPs.

Canonical Wnt signaling is active during developmental myelination and remyelination

Tcf4 can activate or repress target genes of the Wnt pathway through nucleoprotein complex formation with $\beta$-catenin or Groucho/Tle family proteins, respectively (van de Wetering et al. 2002). Tcf repressor function has been reported to regulate patterning of the ventral neural tube (Lei et al. 2006), and it has been suggested that Wnt activity might regulate oligodendrocyte development in the embryonic spinal cord (Shimizu et al. 2005). However, roles for Wnt-catenin signaling in postnatal oligodendrocyte development and myelination have 
A

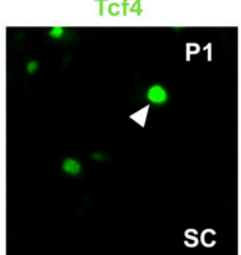

B

Olig1 nuclear

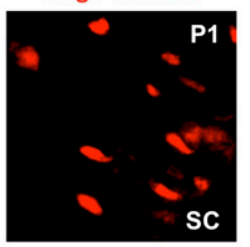

C
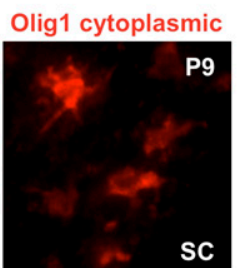

D
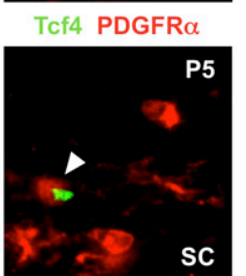

Tcf4 Olig2

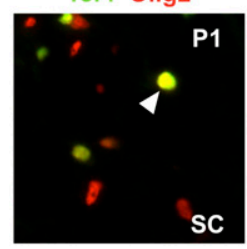

Tcf4

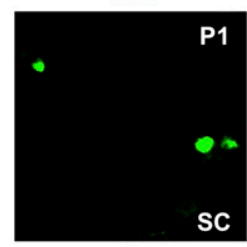

Tcf4

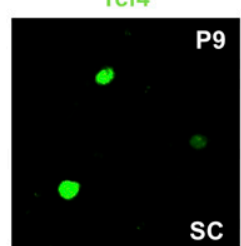

Tcf4 PLP

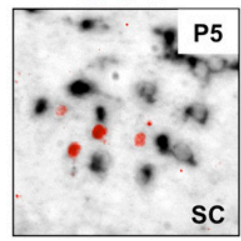

Tcf4

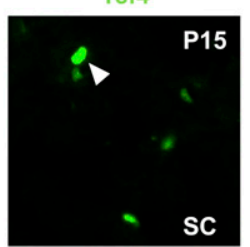

Tcf4 Olig1 DAPI

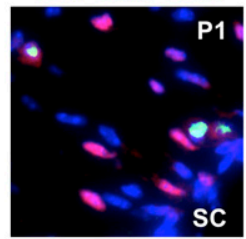

Tcf4 Olig1 DAPI

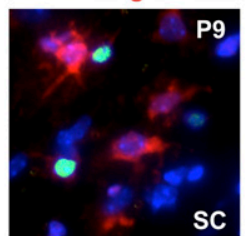

Tcf4 PLP

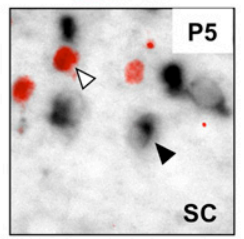

Tcf4 Olig2

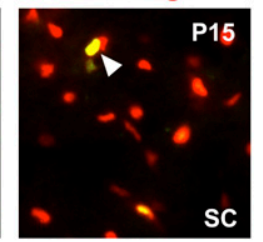

Tcf4 Olig1

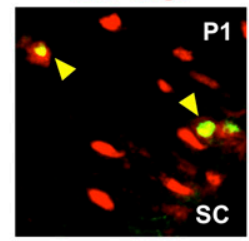

Tcf4 Olig1

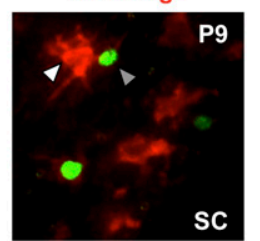

Tcf4 PLP

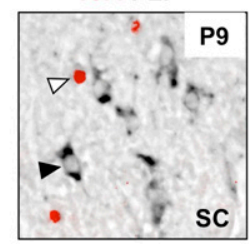

Figure 3. Tcf4 (Tcf712) is expressed in oligodendrocyte lineage during developmental myelination. (A) Tcf4 labels a subset of Olig2 cells at P1 and P15 during developmental myelination of spinal cord white matter. (B) At P1, Olig1 protein is almost entirely nuclear (which we showed previously is a marker for OLPs) (Kitada and Rowitch 2006), and Tcf4 is expressed in a subset of these cells. $(C)$ Tcf4 protein does not colocalize with cytoplasmic Olig1 protein (which we showed previously marks mature oligodendrocytes) (Kitada and Rowitch 2006) at P9. (D) Tcf4 colocalizes with OLP marker PDGFR $\alpha$ protein at P5 but does not colocalize with mature oligodendrocyte marker PLP message at P5 or P9.

not been described in mammalian CNS. To demonstrate $\beta$-catenin-dependent Wnt pathway activation in OLPs, we first used BAT-gal reporter mice (Maretto et al. 2003), in which nuclear $\beta$-galactosidase expression is up-regulated by Tcf- $\beta$-catenin (Fig. 4A). During development, myelination mainly occurs between P0 and P14. We observed reporter activation in NG2-expressing OLPs of P5 corpus callosum, and a subset of Olig2 and Tcf4 cells of $\mathrm{P} 1$ spinal cord white matter (Fig. 4B,C). Groucho expression is essentially ubiquitous in oligodendrocyte lineage cells including some Tcf4-positive cells (Fig. 2D; data not shown); thus, Tcf4 is likely to be associated with Groucho in BAT-gal-negative cells. Expression of the Wnt pathway inhibitor (and mature oligodendrocyte marker) APC (CC1) segregated from reporter activity in P20 corpus callosum (Fig. 4D). We also observed BAT-gal-positive cells in $\sim 15 \%$ of OLPs after induction of demyelination (Fig. 4D). Second, we used an independent (nontransgenic) reporter of Wnt pathway activation to demonstrate pathway activity in oligodendrocyte lineage during remyelination: Axin2 is a known target of Wnt signaling (Lustig et al. 2002) and is up-regulated by activation of the Wnt pathway. Figure 4E shows that endogenous Axin2 mRNA expression occurs within Olig2 cells within the remyelinating lesion. We conclude that $\beta$-catenin-dependent activation of canonical Wnt targets occurs normally during oligodendrocyte development and remyelination.

\section{Dysregulated Wnt- $\beta$-catenin signaling inhibits developmental myelination}

To determine the effect of active canonical Wnt signaling in myelination, we used Olig2-cre (Schüller et al. 2008) to conditionally express floxed dominant-active $\beta$-catenin (DA-Cat) (Harada et al. 1999) in OLPs. Olig2cre/DA-Cat animals were indistinguishable from wild-type littermates at birth and contained normal numbers of OLPs in spinal cord at embryonic day 18 (E18) (Fig. 5A), consistent with onset of Tcf4 expression at P1 (Fig. 5B) and findings above (Figs. 2B, 4B). Subsequently, Olig2cre/DACat mice exhibited severe tremor and ataxia from approximately P6 to P20 (Supplemental Movies). Although the numbers of Tcf $4^{+}$cells were similar, Olig2 ${ }^{+}$cells were reduced in Olig2cre/DA-Cat mice, so that Tcf4 protein was coexpressed in a significantly higher proportion $(P=$ $3.8 \times 10^{-5}$ ) of Olig2 cells at P15 compared with wild-type littermates (Fig. 5C). At P9 and P15, we observed a significant $\left(P=0.0002\right.$ and $P=5.5 \times 10^{-5}$, respectively $)$ reduction in $P L P$-expressing myelinating oligodendrocytes within spinal cord white matter (Fig. 5D,G), despite normal numbers of premyelinating OLPs. Because we found reduced numbers of Olig2 cells (Fig. 5C), which labels OLPs and mature oligodendrocytes, and cell death is associated with wnt pathway activation in zebrafish neural tube (Kim et al. 2008), we performed analysis of Caspase-3 expression. As shown in Supplemental Figure 3, 


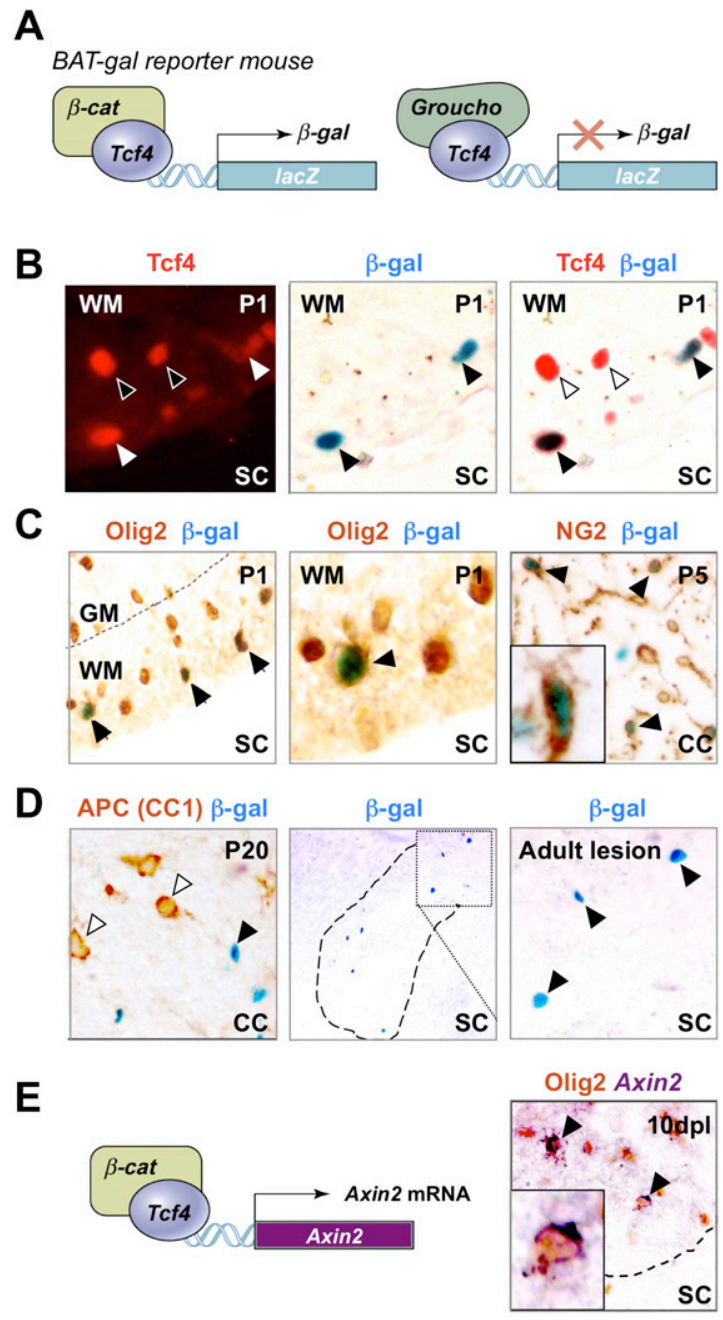

Figure 4. Use of BAT-gal mice demonstrates that Tcf4 functions in catenin-dependent Wnt signaling during brain and spinal cord developmental myelination and remyelination of adult spinal cord. (A) Schematic for Tcf4- $\beta$-catenin-driven $\beta$-galactosidase $(\beta$-gal) reporter expression in BAT-gal mice. $(C) \beta$-gal is expressed in a subset of Olig2 cells in BAT-gal reporter mice in presumptive white matter only of P1 SC, and in a subset of NG2 cells in P5 CC, suggesting that the Wnt pathway is active in these cells. $\beta$-gal is expressed in a subset of Tcf4 cells in BAT-gal Wnt reporter mice P1 SC white matter $(B)$, but is not expressed in cells expressing the Wnt pathway inhibitor APC (CC1) in P20 $\mathrm{CC}(D)$. (D) $\beta$-gal is re-expressed in a demyelinated lesion at $5 \mathrm{dpl}$ following injection of lysolecithin into BAT-gal spinal cord. Filled arrowheads refer to BAT-gal-positive cells. Unfilled arrowheads show Tcf 4 or CC1 staining cells that are BAT-gal-negative. (E) Schematic for Tcf4- $\beta$-catenin-driven Axin-2 mRNA expression. Axin2 is a known target of Wnt signaling (Lustig et al. 2002) that is globally up-regulated by activation of the Wnt pathway. Endogenous Axin-2 mRNA is expressed in a subset of Olig2 cells at $10 \mathrm{dpl}$ in a remyelinating spinal cord lesion.

the reduction in mature oligodendrocytes at $\mathrm{P} 9$ and $\mathrm{P} 15$ in the Olig2cre/DA-Cat cord (Fig. 5D) is not associated with a detectable increase in apoptosis. Together, these findings suggest inhibition of timely oligodendrocyte differentiation in Olig2cre/DA-Cat mice.
Myelin sheath thickness can be quantified by G-ratio analysis (the ratio of the myelinated axon diameter to the axon diameter). As shown in Figure 5, D, E, and $\mathrm{H}$, G-ratios from spinal cord white matter, corpus callosum, and deep cerebellar white matter were all significantly increased (e.g., $P=1.9 \times 10^{-35}$ in spinal cord) in Olig2cre/ DA-Cat mice at P15, indicating generalized hypomyelination. Indeed, because the action of the DA-Cat relies on Tcf, these findings suggest that Tcf4 expression and canonical Wnt pathway activation occur transiently in most -if not all-OLPs contributing to myelination. Further supporting ubiquitous expression and effects of Tcf$\beta$-catenin signaling, we observed dramatically reduced numbers of $P L P$-expressing cells throughout the brain of Olig2cre/DA-Cat mice at P15 (Supplemental Fig. 4). Finally, our data show that developmental hypomyelination from active catenin signaling represented a significant delay-rather than a complete block-in OLP differentiation as G-ratios and $P L P$-expressing cell numbers were substantially normalized in adults (Figs. 5F,I, 7B [below]). This delay is most probably overcome because Tcf4 expression, which is regulated in a Wnt-independent manner (He et al. 2007), becomes down-regulated in $D A$-Cat adult animals, rendering constitutively activated $\beta$-catenin ineffectual.

Evidence that regulation of Wnt- $\beta$-catenin signaling is conserved in the developing human CNS and in MS lesions

To assess conserved Wnt expression in human brain, we first analyzed expression of Tcf4 protein during developmental myelination in corpus callosum. As shown in Figure 6A, Tcf4 was expressed at 1 mo postnatal age, peaked at $3.5 \mathrm{mo}$, declined toward the end of developmental myelination at $16 \mathrm{mo}$, and was absent at $7 \mathrm{yr}$. Tcf 4 expression colocalized with Olig2, suggesting expression in OLPs (Fig. 6A). In the adult rodent CNS, Tcf4 expression was specific to OLPs in lesioned white matter (Fig. 2). Similarly in humans, Tcf4 protein was undetectable in normal adult white matter (Fig. 6B) but was expressed within active areas of MS lesions ( $n=3$ patients), where it colocalized with Olig2 in oligodendrocyte lineage cells (Fig. 6B). Furthermore, we found evidence of WNT pathway gene (Lock et al. 2002) and protein (Han et al. 2008) expression in human MS lesions (Supplemental Fig. 5) including putative Tcf4 targets (Supplemental Fig. 6; Hallikas et al. 2006). Together with expression profiling data from mouse lesions (Supplemental Fig. 2), these findings suggest that Wnt pathway expression is active in human demyelinating lesions.

\section{Dysregulated Wnt- $\beta$-catenin signaling inhibits remyelination}

Neonatal and adult oligodendrocytes have dramatically different responses to certain types of injury (Back et al. 2002). We therefore tested whether Wnt pathway dysregulation-in addition to its effects on developmental myelination-also inhibited remyelination in adult mice. We first analyzed the kinetics and quality of 

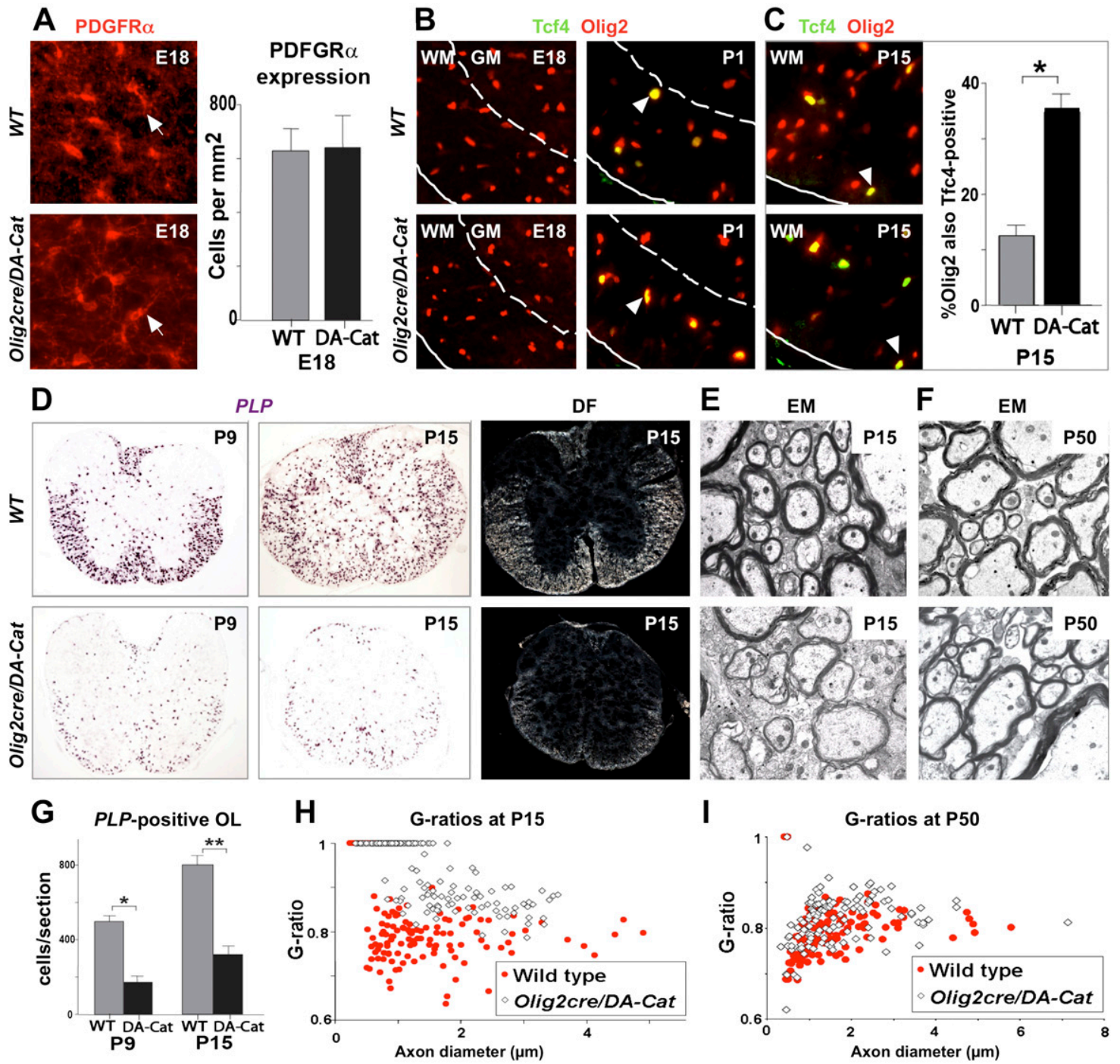

Figure 5. Overexpression of activated $\beta$-catenin in oligodendrocyte lineage cells during development leads to hypomyelination and a significant delay in OLPs to oligodendrocyte differentiation, without affecting the embryonic production of premyelinating OLP. (A) Overexpression of activated $\beta$-catenin in oligodendrocyte lineage cells in Olig2cre/DA-Cat mice does not affect the production of premyelinating PDGFR $\alpha$-expressing OLPs (arrows) in spinal cord at developmental stage E18. (B) Tcf4 protein is not expressed in the spinal cords of wild-type (WT) or Olig2cre/DA-Cat mice at E18, indicating that the Tcf4/activated $\beta$-catenin complex does not affect embryonic production of oligodendrocyte lineage cells, but appears at P1 both in the presumptive white matter in a subset of Olig2 cells (arrowheads). (C) At P15 there is a reduction in the number of Olig2 cells in spinal cord of the Olig2cre/DA-Cat, and Tcf4 is expressed in a higher proportion $\left[\left(^{\star}\right) P=3.8 \times 10^{-5}\right)$ of the Olig2-expressing cells. $(D, G)$ Olig2cre $/ D A$-Cat mice show a marked reduction $\left[(G)\left({ }^{\star}\right) P=\right.$ 0.0002 at $\left.\mathrm{P} 9 ;{ }^{* \star}{ }^{\star}\right) P=5.5 \times 10^{-5}$ at $\left.\mathrm{P} 15\right]$ in the number of mature oligodendrocytes expressing $P L P$ message during myelination at $\mathrm{P} 9$ and P15, with a clear reduction in the white matter visible under dark field (DF) at P15. $(E, H)$ Ataxia and tremor are associated with a significant hypomyelination in Olig2cre/DA-Cat mice, as seen by EM in the P15 spinal cord white matter, and a significant $(P=1.9 \times$ $10^{-35}$ ) reduction in the myelin thickness as assessed by G-ratio analysis. $(F, I)$ The hypomyelination during developmental myelination in Olig2cre/DA-Cat represents a delay in OLP differentiation rather than an irreversible block; myelin appearance and G-ratio are similar to wild-type littermates in the adult P50 white matter.

remyelination following demyelination in adult Olig2cre/DA-Cat animals. This analysis was possible because the developmental hypomyelination in Olig2-cre/DACat animals represented a delay-rather than a complete block-in OLP differentiation, because effects of DA-Cat are mitigated by down-regulation of its obligate partner Tcf4 after P21. Myelin thickness and PLP-expressing cell numbers were normalized in adults (Figs. 5F,I, 7B). As shown, during remyelination in adult Olig2-cre/DACat (Fig. 7A,B), we observed a significant reduction in $P L P$-positive oligodendrocytes $(P=0.028$ at $10 \mathrm{dpl}, P=$ 0.0009 at $14 \mathrm{dpl}$, despite equivalent recruitment of Nkx2.2-expressing OLPs into lesions. G-ratios of remyelinated axons in Olig2-cre/DA-Cat mice were significantly 
Fancy et al.
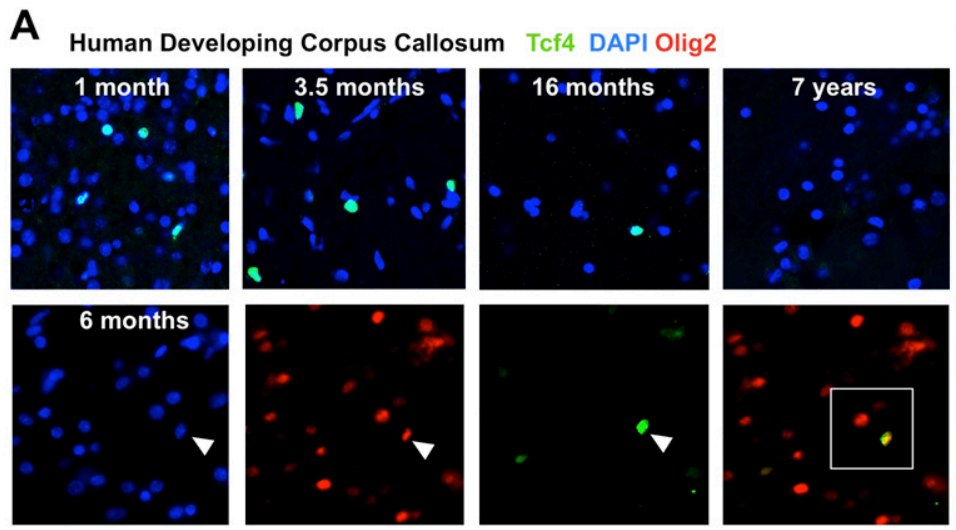

Tcf4+ cells/section
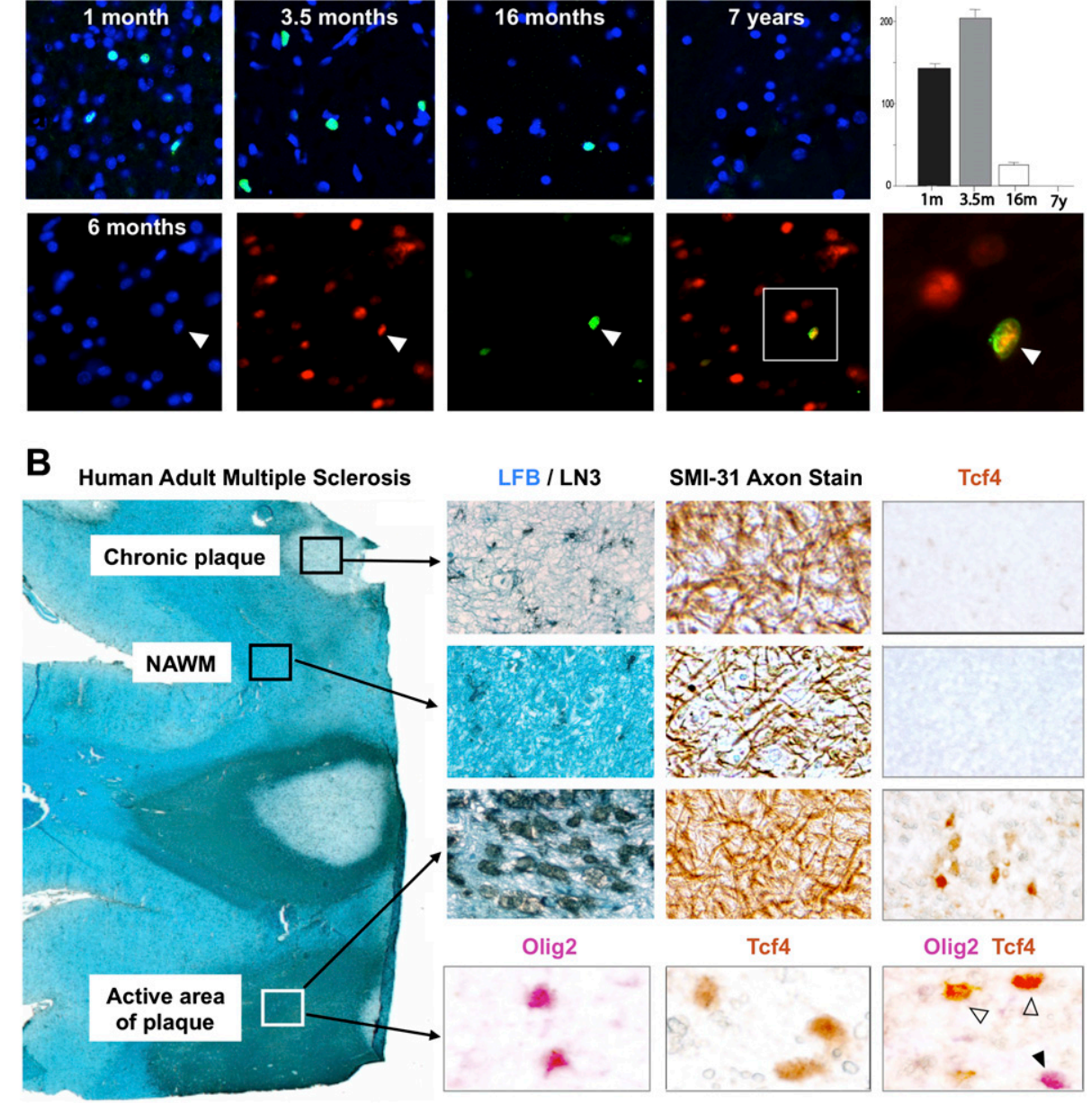

Figure 6. Tcf4 is expressed in oligodendrocyte lineage in human developmental white matter and in active areas of MS lesions. (A) Tcf4 is expressed in white matter tracts during myelination of human developmental brain at postnatal age $1 \mathrm{mo}, 3.5 \mathrm{mo}$, and $16 \mathrm{mo}$, but is not expressed by $7 \mathrm{yr}$. Tcf4 colocalizes with Olig2 when expressed in the developing human corpus callosum. $(B)$ Tcf 4 protein expression is evident in active MS lesions, but it is not seen in normal-appearing white matter (NAWM) or in the core of chronic MS lesions. An illustrative MS case is shown with several lesion types present. NAWM stains with Luxol Fast Blue (LFB) and contains sparse LN3(HLADR)-positive inflammatory cells, organized SMI-31 axon fibers, and no Tcf4-positive cells. Chronic plaques have sparse LFB staining and LN3-positive cells, intact axons, but no Tcf4-positive cells. In contrast, Tcf4-positive cells are present in active areas of plaques with abundant LN3-positive cells and intact demyelinated axons. Tcf4 expression in active lesions colocalizes (open arrowheads) with a subset of Olig2 cells.

$\left(P=4.6 \times 10^{-9}\right)$ increased at $14 \mathrm{dpl}($ Fig. $7 \mathrm{C})$, indicating delayed repair.

In an independent genetic approach to demonstrate the effect of pathway dysregulation on remyelination, targeting a component of the degradation complex for $\beta$-catenin in the Wnt-catenin pathway, we analyzed remyelination in $A P C^{M i n}$ adult mice (Su et al. 1992) that lack one copy of the $\beta$-catenin antagonist APC. Similar to overactivating $\beta$-catenin in the Olig2cre/DA-cat, we also observed significant impairment of remyelination, but not OLP recruitment, in $A P C^{\text {Min }}$ adult mice (Fig. 7D). We confirmed Wnt pathway expression in repairing white matter lesions at $14 \mathrm{dpl}$ by expression profiling (Supplemental Fig. 2; Supplemental Table 2). Taken together, these findings establish that activation of $\beta$-catenin signaling (either by activating $\beta$-catenin itself or reducing activity of a $\beta$-catenin antagonist) inhibits OLP differentiation and repair after demyelinating injury. They further suggest that WNT pathway dysregulation in human MS lesions might contribute to failure of remyelination.

\section{Discussion}

Important insights into the cell-intrinsic mechanisms that regulate OLPs during remyelination have come from genetic analysis of TF-encoding genes (Arnett et al. 2004; He et al. 2007). TFs as a class also have utility as nuclear markers (easy to distinguish from adjacent cells) in translational studies of human pathobiology (Arnett et al. 2004; Ligon et al. 2004; Kuhlmann et al. 2008). From 
A
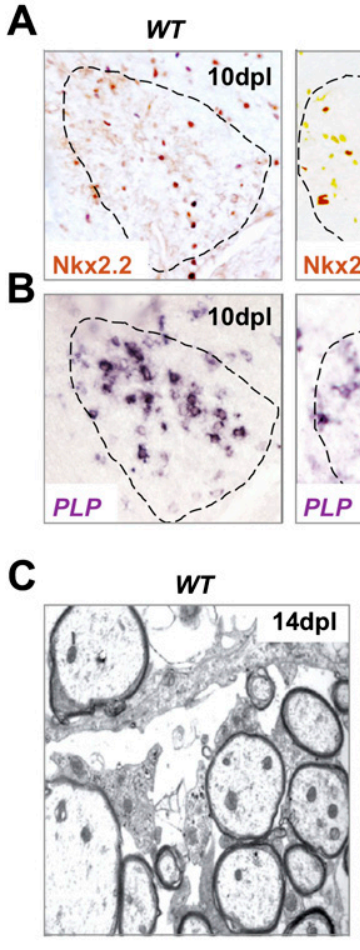

C

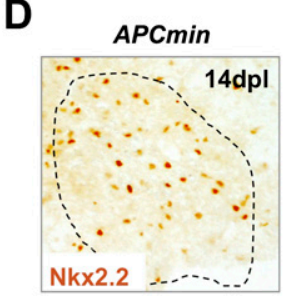

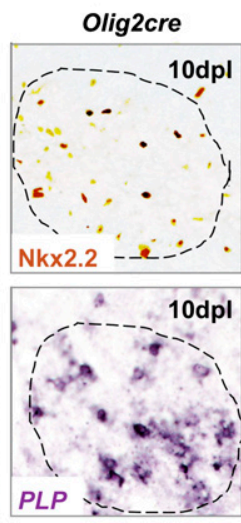

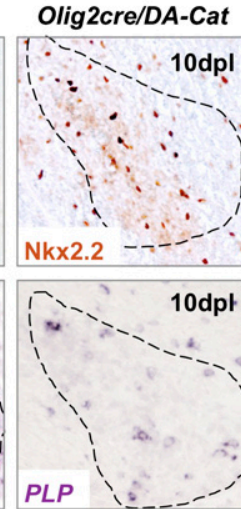

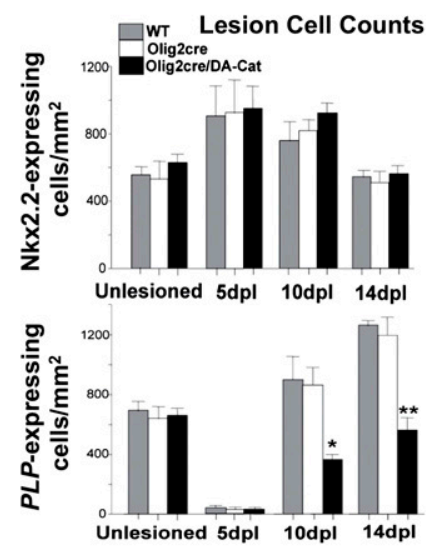

G-ratios at $14 \mathrm{dpl}$

Olig2cre/DA-Cat
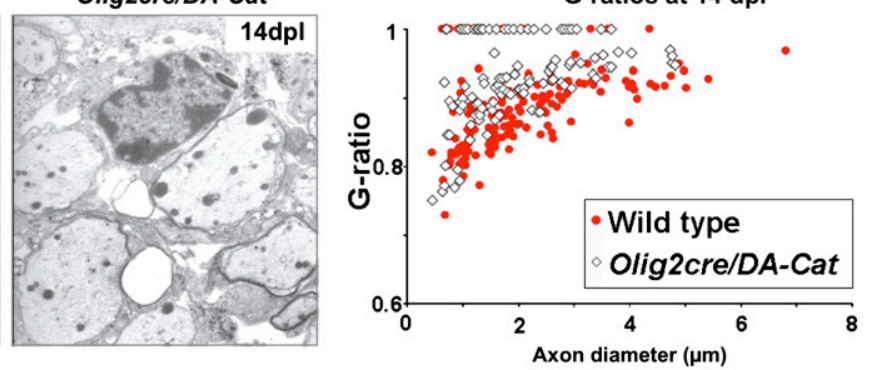

WT
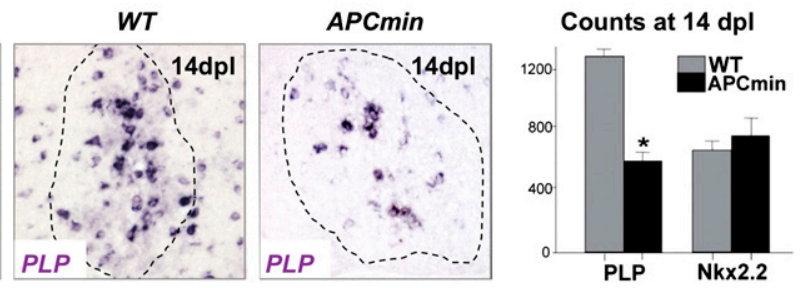

Figure 7. Overexpression of activated $\beta$-catenin in oligodendrocyte lineage cells during remyelination in the adult causes a delay in repair due to a delay in OLP differentiation, without affecting their recruitment into the lesion. $(A)$ Similar numbers of OLPs expressing Nkx2.2 protein, are present within remyelinating adult spinal cord lesions at $10 \mathrm{dpl}$ in wild type (WT), Olig2cre control, and Olig2cre/ $D A$-Cat mice, and also at $5 \mathrm{dpl}$ and $14 \mathrm{dpl}$ in wild type (gray bars), Olig2cre control (white bars), andOlig2cre/DA-Cat mice (black bars). $(B)$ There is a significant reduction $\left[{ }^{*}\right) P=0.028$ at $10 \mathrm{dpl}_{;}\left(^{\star \star}\right) P=0.0009$ at $\left.14 \mathrm{dpl}\right]$ in the subsequent differentiation of recruited OLPs into mature remyelinating oligodendrocytes expressing PLP message during remyelination in the Olig2cre/DA-Cat (black bars) compared with wild type (gray bars) or Olig2cre controls (white bars). (C) Delay in OLP differentiation during remyelination results in thinner myelin sheaths at $14 \mathrm{dpl}$ in Olig2cre/DA-Cat mice evident by EM, and with significant $\left(P=4.6 \times 10^{-9}\right)$ change in G-ratio. $(D)$ APCmin mice, lacking one allele of the Wnt pathway inhibitor APC, show a marked deficit in remyelination of adult spinal cord at 14 dpl, due to a significant reduction $\left[\left(^{\star}\right) P=0.012\right]$ of differentiation into mature $P L P$-expressing oligodendrocytes, despite normal recruitment of $\mathrm{Nkx} 2.2$-expressing OLPs.

an ISH expression screen of 1040 TF-encoding genes (Gray et al. 2004) ( $\sim 70 \%$ of all genes in this class in the mammalian genome) in tissue arrays of remyelinating rodent lesions at 5, 10, and $14 \mathrm{~d}$ post-injection of lysolethicin, we found $>50$ genes expressed at various key stages during the myelin repair process, associated with various cell types including oligodendrocyte lineage cells, astrocytes, or inflammatory cells (Ghasemlou et al. 2007). Systematic functional screens are in progress to identify potentially complex regulatory networks of TFs in oligodendrocytes during myelin repair. Here we focused on expression of Tcf4 and actions of dysregulated Wnt signaling.
'Dysregulation' of remyelination as a mechanism leading to chronic demyelination in human white matter diseases

A comprehensive explanation of why remyelination is so limited in some patients with MS, even though endogenous oligodendrocyte lineage cells are often present within lesions, remains elusive (Miller and Mi 2007; Franklin and Ffrench-Constant 2008). Nonremyelinating chronic lesions observed in MS have been proposed to result from dysregulation of any of several steps in the remyelination process (Miller and Mi 2007; Franklin and Ffrench-Constant 2008). Although it is possible that the 
persistent expression of only one or two key inhibitors of remyelination might act as "master regulators" of this process, having dominating effects to prevent remyelination, we proposed that nonremyelinating chronic lesions could result from dysregulation of multiple steps in the remyelination process, resulting in a failure of the normal coordinated repair response (Franklin and FfrenchConstant 2008).

The finding of OLPs and premyelinating oligodendrocytes in chronic lesions of MS suggest that remyelination is most vulnerable during their differentiation rather than their recruitment (Wolswijk 1998; Chang et al. 2002; Kuhlmann et al. 2008). Accordingly, if the expression of one or more differentiation inhibitors is inappropriately prolonged, OLPs may miss this critical window of opportunity for differentiation and therefore persist in an undifferentiated state as lesions develop into chronic areas of persistent demyelination. While other inhibitors of differentiation are proposed to have roles in remyelination (Charles et al. 2002; John et al. 2002; Back et al. 2005; Mi et al. 2005), we show here the first in vivo functional evidence that dysregulation of a candidate pathway within OLPs can inhibit kinetics of differentiation during myelin repair.

Canonical Wnt pathway activation and dysregulation profoundly delay oligodendrocyte myelination during development and repair

We performed a de novo whole-genome in situ expression-based screen using a unique library of 1040 probes for TF-encoding genes (Gray et al. 2004), identifying 50 genes showing altered expression within remyelinating lesions. We focused on the obligate Wnt pathway transcriptional mediator Tcf4, based on expression in oligodendrocyte lineage cells specific to injured white matter in the adult brain of rodents and humans, including OLPs of active human MS lesions. We found widespread activation of the Wnt pathway in experimental remyelinating lesions and through data mining of published studies on human MS lesions (Lock et al. 2002; Han et al. 2008). Thus, Wnt pathway expression is a conserved feature of demyelinated lesions in the mammalian CNS.

Previous work has indicated that oligodendrocytes are born in multiple waves during development (Cai et al. 2005; Vallstedt et al. 2005; Kessaris et al. 2006) and that neonatal and adult oligodendrocytes may have a dramatically different response to injury (Back et al. 2002), possibly reflecting changes in dependence on underlying regulatory mechanisms. Tcf4 expression by itself does not indicate Wnt pathway activation, as Tcf4 can act as both a cofactor in Wnt target gene activation (e.g., in association with $\beta$-catenin) or repression (e.g., when associated with Groucho). To show that canonical Wnt signaling was active in oligodendrocytes in vivo, we analyzed expression of the Wnt gene target Axin2 (Lustig et al. 2002), as well as BAT-gal reporter mice that contain Tcf4responsive regulatory sequences designed to express the reporter gene only when bound by the canonical Tcf4$\beta$-catenin complex (Maretto et al. 2003). This indicated that Wnt signaling was active transiently during postnatal oligodendrocyte development. We also confirmed activation of the Wnt pathway in remyelinating lesions.

Activation of $\beta$-catenin inhibited developmental myelination and remyelination in rodents, and we show that the activated $\beta$-catenin/Tcf 4 complex can act as an inhibitor of OLP differentiation in the mammalian CNS, a conclusion supported by recent investigation of frz 8 function in zebrafish (Kim et al. 2008). Furthermore, $A P C^{M i n}$ animals, which lack one copy of the catenin antagonist $A P C$, also exhibited impaired remyelination, indicating that Wnt pathway regulation is critical for timely myelination and remyelination. Although roles for the Wnt pathway have not been recognized previously in myelination, it is interesting to note that APC is an established marker of mature oligodendrocytes (Fig. 8). Indeed, based on our findings, $\beta$-catenin antagonists in general are predicted to regulate myelin formation. We were not able to establish critical roles for $\beta$-catenin in OLP postnatal myelination owing to $92 \%$ postnatal lethality of Olig2-cre $X \beta$-catenin(fl/fl) animals (Brault et al. 2001), and we failed to detect precocious myelination in brain or spinal cord at P1 (Supplemental Fig. 7). In addition to frizzled receptors, $\beta$-catenin signaling can be activated downstream from heterologous receptors (Nelson and Nusse 2004). For instance, PDGFR $\alpha$, characteristically expressed in OLPs, can activate $\beta$-catenin through c-Abl-p68 (Yang et al. 2006). Further work is needed

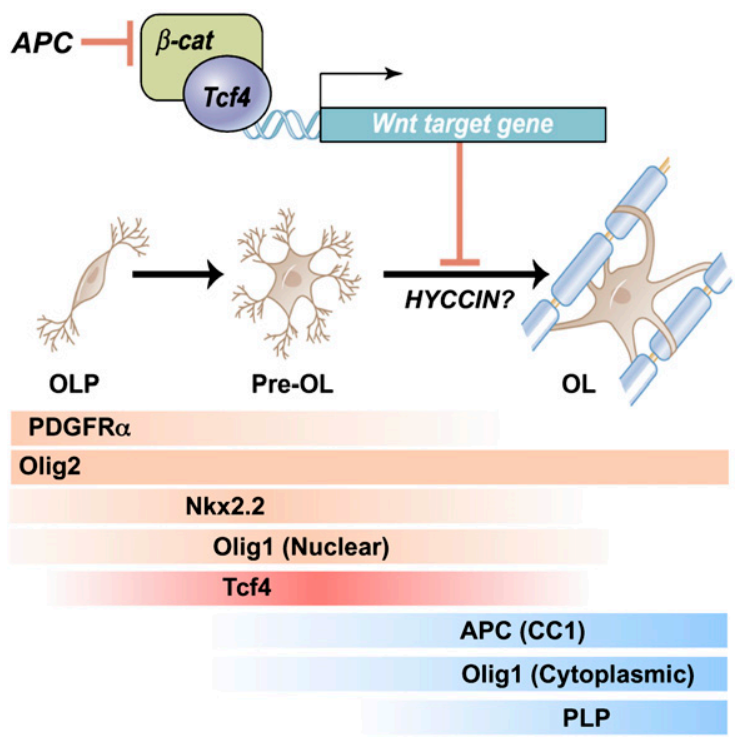

Figure 8. Scheme indicating expression of Tcf4 proteins and effects of Wnt- $\beta$-catenin signaling to inhibit the transition from premyelinating to mature oligodendrocyte. Our genetic evidence is consistent with APC (CC1, a known marker of mature oligodendrocytes) acting to promote differentiation. HYCCIN, a Wnt-repressed target (Kawasoe et al. 2000) with essential roles in human myelination (Zara et al. 2006), is expressed in rodent oligodendrocytes and down-regulated in Olig2cre/DA-Cat mice (Supplemental Fig. 8). Temporal expression of Tcf4 and markers of oligodendrocyte lineage tested in this study is shown. (Pre OL) Premyelinating oligodendrocyte; $(\mathrm{OL})$ oligodendrocyte. 
to determine the nature of Wnt and/or other ligands in the lesion environment that functionally regulate $\beta$-catenin activation and the cellular source of such signals.

\section{Potential Tcf4-catenin activities in oligodendrocyte development}

The pattern of Tcf4 protein expression, from P1 to P30 and during remyelination after injury, defines the window of potential canonical Wnt pathway functions. Within this context, we observed that Tcf4 expression marked $\sim 15 \%-20 \%$ of OLPs at any given stage assessed. These findings were consistent with two possibilities. First, Tcf4 expression could demarcate a subset of OLPs. Second, it was possible that Tcf4 expression transiently marks all (or the vast majority) of OLPs during development. Our functional evidence strongly supports the latter conclusion, based on the fact that activity of activated $\beta$-catenin is Tcf-dependent (van de Wetering et al. 2002), coupled with the robust phenotype in DA-Cat and $A P C^{M i n}$ animals, in which we observe pervasive effects of Wnt pathway dysregulation on myelin production throughout the CNS. Interestingly, although Tcf4 proteins are coexpressed with nuclear Olig1 proteins, Tcf4 segregated from cells expressing Olig1 mRNA transcripts, consistent with the possibility that Tcf4 is expressed at a transition stage when nuclear Olig1 proteins become down-regulated during remyelination.

Previous work has suggested inhibitory functions of Tcf4 on myelin basic protein gene expression in vitro (He et al. 2007), and our studies indicate that Tcf4 interactions with $\beta$-catenin inhibit myelination in vivo. Additional studies are warranted to rule out possible $\beta$-catenin-independent roles for Tcf4 in oligodendrocyte development. Although Wnt pathway activation has conventionally been thought of as activating gene targets, recent work has identified novel Tcf- $\beta$-catenin DNA regulatory binding sites that repress targets (Blauwwkamp et al. 2008). In this regard, one intriguing candidate target is HYCCIN (DRCTNNB1A), a Wnt-repressed target (Kawasoe et al. 2000) with essential roles in human myelination (Zara et al. 2006), which is expressed in rodent oligodendrocytes and down-regulated in Olig2cre/DA-Cat mice (Supplemental Fig. 8). Further studies are needed to better understand Tcf4-catenin function and its direct gene targets during oligodendrocyte lineage progression.

Wnt pathway dysregulation in OLPs as a mechanism leading to chronic demyelination in human white matter diseases

Therapeutic opportunities might arise from an enhanced understanding of the process regulating normal kinetics of remyelination. How might the negative regulatory role of the canonical Wnt pathway help to explain the pathology of demyelinating disease? Delayed remyelination due to Wnt pathway dysregulation in OLPs could lead to chronic demyelination by OLPs then missing a "critical window" for differentiation (Miller and Mi 2007; Franklin and Ffrench-Constant 2008). This "dysregulation model" of remyelination failure requires the
Wnt pathway to be active during acute demyelination, as suggested by data from our animal systems and human MS tissue.

Canonical WNT signaling has been implicated in a variety of human diseases (Nelson and Nusse 2004), and gain-of-function mutations in $\beta$-catenin are etiologic in several cancers including the majority of colon adenocarcinomas. Approaches for treating Wnt-dependent cancers by promoting differentiation (and hence cell cycle arrest or apoptosis) using pharmacological inhibitors of the pathway are under development (Barker and Clevers 2005). It is possible that such antagonists might play a role in the therapeutic enhancement of remyelination by normalizing the kinetics of myelin repair. If so, the animal models described here (e.g., $A P C^{+-}$) should be useful in preclinical testing. However, it is important to note that while dysregulation of a pathway might delay remyelination, it is overly simplistic to expect that inhibition of the same pathway would accelerate repair in the complex milieu of an MS lesion in which several inhibitory pathways might be active, compounded by the presence of myelin debris (Kotter et al. 2006). Indeed, because of the need to synergize with other processes (e.g., those associated with inflammation), accelerated differentiation might negatively affect repair (Franklin and Ffrench-Constant 2008). Further work is needed to comprehensively understand interactions of regulatory networks required for optimal remyelination and how these may be dysregulated in human demyelinating diseases.

\section{Materials and methods}

\section{Induction of demyelination in CNS}

Demyelinated lesions were produced in the ventrolateral spinal cord white matter of 8- to 10-wk-old Olig2cre/DA-Cat, APC ${ }^{\text {min }}$, Olig2cre/ $\beta$-cat(f1/f1), Olig2cre control, and wild-type littermate mice. Anesthesia was induced and maintained with inhalational isoflurane/oxygen, supplemented with $0.05 \mathrm{~mL}$ of buprenorphine (Vetergesic $0.05 \mathrm{mg} / \mathrm{mL}$ ) given subcutaneously. Having exposed the spinal vertebrae at the level of $\mathrm{T} 12 / \mathrm{T} 13$, tissue was cleared overlying the intervertebral space, and the dura was pierced with a dental needle just lateral to midline. A Hamilton needle was advanced through the pierced dura at an angle of $45^{\circ}$ and $0.5 \mu \mathrm{L}$ of $1 \%$ lysolecithin (L- $\alpha$-lysophosphatidylcholine) was injected into the ventrolateral white matter. Induction of demyelination with $\mathrm{EtBr}$ in rat CCP and induction of demyelination with cuprizone in mouse corpus callosum were performed as described previously (Arnett et al. 2004).

TF whole-genome in situ expression screen (Mahoney Screen) of remyelination in adult CNS

A total of 1040 putative TFs were previously identified in the mouse genome (Gray et al. 2004), and probes were made for ISH to identify their expression in vivo. This probe set was used to screen TF expression during CNS remyelination following experimentally induced demyelination. Adult 8- to 10 -wk-old wildtype animals in which focal demyelination was induced by lysolecithin injection were euthanized at three survival time points: $5 \mathrm{dpl}$, representing peak OLP recruitment; $10 \mathrm{dpl}$, representing onset of OLP differentiation; and $14 \mathrm{dpl}$, representing new myelin sheath formation ( $n=10$ for each survival time) and 
perfused with $4 \%$ paraformaldehyde in phosphate-buffered saline (PBS) via the ascending aorta. Lengths of spinal cord containing the lesion were dissected and immediately immersed in $30 \%$ sucrose in PBS prior to transverse cryosectioning at $12-\mu \mathrm{m}$ thickness. More than 1200 glass slides were prepared, such that each slide had one section for each of the three survival times (see Fig. 1A). Each slide was screened by ISH (ISH method described previously) (Gray et al. 2004) for an individual probe from the probe set, such that the expression of each TF could be assessed at the three survival times.

\section{Mice}

Olig2-tva-cre. A multifunctional mouse line was constructed previously (Schüller et al. 2008) by inserting tva, an avianspecific retroviral receptor, and an IRES-cre recombinase cassette into the endogenous Olig2 locus by homologous recombination. This Olig2-cre allowed for cre-mediated activity in oligodendrocyte lineage cells.

DA-Cat. The serine/threonine residues (i.e., S33, S37, T41, and S45) within exon 3 of $\beta$-catenin are targets for phosphorylation by GSK3 $\beta$, leading to subsequent degradation of the $\beta$-catenin. The DA-Cat mouse was produced previously (Harada et al. 1999) and has exon 3 of the mouse $\beta$-catenin gene located between lox $P$ sequences together with a neo selection cassette. Cre recombinase-mediated deletion of exon 3 produces a dominant-stable mutant $\beta$-catenin protein. Crossing of DA-Cat mice to Olig2-cre ${ }^{+/-}$ mice produces a proportion of offspring heterozygous for both. These mice have one normal allele for $\beta$-catenin and one dominant-stable allele within oligodendrocyte lineage cells.

BAT-gal. Production of the BAT-gal $(\beta$-catenin-activated transgene driving expression of nuclear $\beta$-galactosidase reporter) mouse has been described previously (Maretto et al. 2003). BAT-gal was constructed by fusing seven TCF/LEF-binding sites upstream of a $0.13-\mathrm{kb}$ fragment containing the minimal promoter-TATA-box of the gene siamois, driving expression of downstream nuclear $\beta$-galactosidase reporter. This transgenic can be used to identify Wnt $/ \beta$-catenin-responding cells in vivo. The construct leads to a specific lac $Z$ reporter gene activation on $\mathrm{Wnt} / \beta$-catenin stimulation, and indeed requires a physical interaction between activated $\beta$-catenin and Tcf for activation to occur.

IHC. Mice were perfused intracardially with $4 \%$ paraformaldehyde, and CNS samples were processed for cryosectioning. Cryosections cut at $12 \mu \mathrm{m}$ thickness were air-dried, heated for antigen retrieval (Dako antigen retrieval; except for NG2, PDGFR $\alpha$, and APC), blocked with $10 \%$ normal goat serum in $0.3 \%$ Triton X-100/PBS, and incubated overnight at $4^{\circ} \mathrm{C}$ in primary antibody in $2 \%$ goat serum and $0.1 \%$ Triton/PBS. The primary antibodies used were as follows: Tcf4 (mouse monoclonal 6H5-3; Upstate Biotechnologies), Tcf4 (mouse monoclonal 1A9; Abnova), Tcf4 (rabbit monoclonal C9B9; Cell Signaling Technology), Olig2 (rabbit polyclonal from CD Stiles; Harvard), Olig1 (rabbit polyclonal from CD Stiles; Harvard), NG2 (a generous gift from W.B. Stallcup, Burnham Institute, La Jolla, CA), Nkx2.2 (mouse monoclonal, Developmental Studies Hybridoma Bank), PDGFR $\alpha$ (rat 558774; BD Biosciences), APC (CC1; mouse monoclonal OP80; Calbiochem), and Tle1 (rabbit polyclonal; Santa Cruz Biotechnologies). Secondary fluorescent antibodies from Alexa were used for immunofluorescent detection, or alternatively the chromagen DAB (Vector Laboratories) was used for detection. Immunopositive cells within lesions were counted once the extent of the demyelination had been established with solochrome cyanine staining on adjacent sec- tions. Cells were counted on three or more nonadjacent sections per mouse and averaged for that mouse; cell counts are presented as an average from at least four mice per time point \pm standard error. Statistical comparisons of cell counts were established using the $t$-test.

Combination IHC with X-gal staining. For combinations of Olig2, Tcf4, or APC IHC with X-gal staining in the BAT-gal mice, IHC was first performed as described above but without antigen retrieval. Following detection with either fluorescent secondary or $\mathrm{DAB}$ chromagen, sections were washed thoroughly in $\mathrm{PBS}$; washed three times for $2 \mathrm{~min}$ in PBS, $2 \mathrm{mM} \mathrm{MgCl}_{2}, 0.02 \% \mathrm{NP}$ 40 , and $0.01 \% \mathrm{Na}$-deoxycholate; then incubated overnight at $37^{\circ} \mathrm{C}$ in staining buffer $\left[30 \mathrm{mM} \mathrm{K}_{4} \mathrm{Fe}(\mathrm{CN})_{6}, 30 \mathrm{mM} \mathrm{K}_{3} \mathrm{Fe}(\mathrm{CN})_{6}\right.$. $3 \mathrm{H}_{2} \mathrm{O}, 2 \mathrm{mM} \mathrm{MgCl} 2,0.01 \%$ Na-deoxycholate, $0.02 \% \mathrm{NP}-40$ in PBS] with $1 \mathrm{mg} / \mathrm{mL}$ X-gal.

Electron microscope histological analysis of developmental myelination and remyelination in the adult, and G-ratio analysis. Mice were euthanized at developmental age P15 and at $14 \mathrm{dpl}$ in adult mice under deep anesthesia by perfusion via the left ventricle with $4 \%$ glutaraldehyde. Fixed spinal cords were removed and post-fixed overnight in the same fixative solution, and then cut transversely into $1.5-\mathrm{mm}$-thick blocks. Blocks were further fixed in osmium tetroxide overnight at $4^{\circ} \mathrm{C}$, dehydrated through ascending ethanol washes, and embedded in TAAB resin (TAAB Laboratories). One-micrometer sections were cut, stained with toluidine blue, and examined by light microscopy, from which remyelination was identified using standard morphological criteria. In addition, selected blocks were trimmed and examined by electron microscopy (Hitachi; H600).

The G-ratio of axons in the area of interest was obtained as a ratio of the diameter of an axon over the diameter of axon plus associated myelin sheath. Briefly, the images of transverse sections in the normal or lesioned white matter of the ventral column of the spinal cord were taken at $6000 \times$ magnification. Digitized and calibrated images were used for morphometric analysis using Scion Image software. Since the axons are often distorted after tissue processing, the required diameters were calculated from the measured perimeters of axon membrane and that of the outside edge of the myelin sheath.

\section{Human MS tissue and double IHC}

Human post-mortem tissue blocks were provided by the UK Multiple Sclerosis Tissue Bank at Imperial College London. All tissues were collected following fully informed consent by the donors via a prospective donor scheme following ethical approval by the London Multicentre Research Ethics committee (MREC 02/2/39). MS lesions were characterized according to Lock et al. (2002), using Luxol Fast Blue to assess demyelination, SMI-31 IHC to assess preservation of axons, and LN3 IHC to assess inflammatory cell activity. Lesions with florid parenchymal and perivascular inflammatory cell infiltration, myelin fragmentation, and demyelination with indistinct margins were classified as active plaques. Chronic active plaques were classified as those with extensive demyelination, well-demarcated borders, and abundant inflammatory cells at the lesion edge. Chronic plaques were classified as those with extensive demyelination, welldemarcated borders but few or no inflammatory cells in any part of the demyelinated area. For IHC on fresh frozen human tissue, sections were air-dried, pretreated with $0.3 \%$ hydrogen peroxide in methanol to quench endogenous peroxidase activity, exposed to a heat antigen retrieval, and processed as in the "IHC" section above. The chromagens DAB (Vector Laboratories) giving a brown coloration for use with Tcf4, and VIP (Vector Laboratories) giving 
a purple coloration with Olig2, were used for double IHC in adult human tissue; colocalization produces a dark orange coloration.

\section{Human developmental tissue}

All normal human tissue was collected in accordance with the University of California at San Francisco Committee on Human Research (H11170-19113-07). Human tissue was obtained with appropriate consent from autopsied material at (1) the University of California at San Francisco Medical Center and (2) the NICHD Brain and Tissue Bank for Developmental Disorders at the University of Maryland, Baltimore, MD. The role of the NICHD Brain and Tissue Bank is to distribute tissue, and, therefore, cannot endorse the studies performed or the interpretation of the results.

Normal human tissue was collected from pediatric patients who died from either traumatic injury or sudden infant death syndrome (SIDS). All patients underwent examination by a neuropathologist and had no evidence of neurologic or system illness. The post-mortem interval ranged from 6 to $12 \mathrm{~h}$, and all tissue was flash-frozen in liquid nitrogen as $1-\mathrm{cm}$ coronal hemispheric slabs at the time of autopsy. Following $30-\mu \mathrm{m}$ cryostat sectioning, fluorescent IHC was performed using the PerkinElmer Renaissance Tyramide Signal Amplification (TSA) System. Briefly, slides were incubated for $10 \mathrm{~min}$ in $95^{\circ} \mathrm{C}$ citrate buffer ( $\mathrm{pH}$ 6.0) and then fixed in 4\% paraformaldehyde for $5 \mathrm{~min}$ at room temperature. Endogenous peroxidases were quenched for $45 \mathrm{~min}$ at room temperature using $0.3 \% \mathrm{H}_{2} \mathrm{O}_{2}$ in methanol. The standard TSA protocol was then applied, using the primary antibody Tcf4 (rabbit monoclonal; Cell Signaling Technology) and a biotin-SP-conjugated AffiniPure goat anti-rabbit IgG secondary antibody (1:200; Jackson ImmunoResearch). All tissue was counterstained using DAPI (1:5000) mounted with Aqua Polymount (Polysciences). Image analysis was performed using a Nikon FN1 upright spectral confocal microscope.

Microarray analysis of remyelinating lesions in adult wild-type mice I: generating microarrays

Microarray expression profiling was used to compare adult wildtype unlesioned white matter with wild-type remyelinating white matter at $14 \mathrm{~d}$ post-demyelination. Unlesioned spinal cords or 14-dpl lesioned cords were removed fresh and snapfrozen in iso-pentane and stored at $-80^{\circ} \mathrm{C}$. Cords were subsequently cut as $50-\mu \mathrm{m}$-thick cryosections, and unlesioned white matter or 14-dpl lesions were manually isolated from the sections using a micro-scalpel (Fine Science Tools 10318-14). Approximately 80 sections were cut from each spinal cord to obtain $1 \mu \mathrm{g}$ of RNA. RNA was extracted using the RNAqueousMicro kit (Ambion), and RNA quality was checked on an Agilent Bioanalyser. Microarray analysis was performed at the Molecular Genetics Core Facility, Children's Hospital Boston. For each of unlesioned white matter and 14-dpl lesions, RNA from three animals was pooled for use in each array chip, and three Affymetrix Mouse Genome 4302.0 chips were run for each group, for a total of nine animals for each group of unlesioned white matter and 14-dpl lesions. Data are available at http:// www.ncbi.nlm.nih.gov/geo.

Microarray analysis of remyelinating lesions in adult wild-type mice II: analyzing microarrays

.cel files were imported into BRB-array Tools (Biometrics Research Branch, NIH), and RMA normalization was carried out. In order to find differentially expressed genes, class comparison analysis was performed between normal white matter and 14-dpl samples. In this analysis, the mean expression of each probe set is compared for the two groups using a random-variance $t$-test. Genes were considered statistically significant if their $P$-value was $<0.001$. A stringent significance threshold was used to limit the number of false-positive findings. We identified genes that were differentially expressed among the two classes by using a multivariate permutation test. We used the multivariate permutation test to provide $90 \%$ confidence that the false discovery rate was $<10 \%$. The false discovery rate is the proportion of the list of genes claimed to be differentially expressed that are false-positives. The test statistics used are random variance $t$-statistics for each gene. Although $t$-statistics were used, the multivariate permutation test is nonparametric and does not require the assumption of Gaussian distributions.

\section{Cell counts and statistical measures}

For all cell counts, at least four animals per genotype were used for each time point indicated. Cells were counted on three or more nonadjacent sections per mouse and presented as an average \pm standard error. Statistical comparisons of cell counts were established using a Student's $t$-test.

\section{Acknowledgments}

We thank Dr. A. Koh for help with expression profiling samples; Dr. C. Stiles for Olig1 and Olig2 antibody; Dr. S. Pleasure for discussion and providing reagents; and Drs. S. Hauser, T. Golub, and B. Vogelstein for helpful comments on the work. We are also grateful to anonymous reviewers for suggestions that improved the work. Professor M.M. Taketo (Kyoto University, Japan) generously provided activated catenin mice. We are grateful to Professor R. Reynolds and the United Kingdom MS Society Brain Bank (Imperial College, London) for supplying MS tissue. All tissues were collected with approval by the London Multicentre Research Ethics committee (MREC 02/2/39). Animal procedures were performed under a UK Home Office Project License or approved by University of California at San Francisco oversight committee. This work was supported by grants from the National Multiple Sclerosis Society (to S.E.B, R.J.M.F., and D.H.R.), the United Kingdom Multiple Sclerosis Society (to R.J.M.F), and the NIH (to D.H.R.). D.H.R. is an HHMI Investigator.

\section{References}

Arnett HA, Fancy SP, Alberta JA, Zhao C, Plant SR, Kaing S, Raine CS, Rowitch DH, Franklin RJM, Stiles CD. 2004. $\mathrm{bHLH}$ transcription factor Olig1 is required to repair demyelinated lesions in the CNS. Science 306: 2111-2115.

Back SA, Han BH, Luo NL, Chricton CA, Xanthoudakis S, Tam J, Arvin KL, Holtzman DL. 2002. Selective vulnerability of late oligodendrocyte progenitors to hypoxia-ischemia. I Neurosci 22: 455-463.

Back SA, Tuohy TM, Chen H, Wallingford N, Craig A, Struve J, Luo NL, Banine F, Liu Y, Chang A, et al. 2005. Hyaluronan accumulates in demyelinated lesions and inhibits oligodendrocyte progenitor maturation. Nat Med 11: 966-972.

Barker N, Clevers H. 2005. Mining the Wnt pathway for cancer therapeutics. Nat Rev Drug Discov 5: 997-1014.

Barres BA, Lazar MA, Raff MC. 1994. A novel role for thyroid hormone, glucocorticoids and retinoic acid in timing oligodendrocyte development. Development 120: 1097-1108.

Blakemore WF, Franklin RJM. 2008. Remyelination in experimental models of toxin-induced demyelination. Curr Top Microbiol Immunol 318: 193-212. 
Blauwwkamp TA, Chang MV, Cadigan KM. 2008. Novel TCF-binding sites specify transcriptional repression by Wnt signalling. EMBO I 27: 1436-1446.

Brault V, Moore R, Kutsch S, Ishibashi M, Rowitch $\mathrm{DH}_{\text {, }}$ McMahon AP, Sommer L, Boussadia O, Kemler R. 2001. Inactivation of the $\beta$-catenin gene by Wnt1-Cre-mediated deletion results in dramatic brain malformation and failure of craniofacial development. Development 128: 1253-1264.

Cai J, Qi Y, Hu X, Tan M, Liu Z, Zhang J, Li Q, Sander M, Qiu M. 2005. Generation of oligodendrocyte precursor cells from mouse dorsal spinal cord independent of $\mathrm{Nkx} 6$ regulation and Shh signaling. Neuron 45: 41-53.

Chang A, Tourtellotte WW, Rudick R, Trapp BD. 2002. Premyelinating oligodendrocytes in chronic lesions of multiple sclerosis. N Engl J Med 346: 165-173.

Charles P, Reynolds R, Seilhean D, Rougon G, Aigrot MS, Niezgoda A, Zalc B, Lubetzki C. 2002. Re-expression of PSA-NCAM by demyelinated axons: An inhibitor or remyelination in multiple sclerosis? Brain 125: 1972-1979.

Compston A, Coles A. 2008. Multiple sclerosis. Lancet 372: 1502-1517.

Franklin RJM, Ffrench-Constant C. 2008. Remyelination in the CNS: From biology to therapy. Nat. Rev. Neurosci. 9: 839855.

Frohman EM, Racke MK, Raine CS. 2006. Multiple sclerosis-The plaque and its pathogenesis. N Engl J Med 354: 942-955.

Ghasemlou N, Jeong SY, Lacroix S, David S. 2007. T cells contribute to lysophosphatidylcholine-induced macrophage activation and demyelination in the CNS. Glia 55: 294-302.

Gray PA, Fu H, Luo P, Zhao Q, Yu J, Ferrari A, Tenzen T, Yuk DI, Tsung EF, Cai Z, et al. 2004. Mouse brain organization revealed through direct genome-scale TF expression analysis. Science 306: 2255-2257.

Hallikas O, Palin K, Sinjushina N, Rautiainen R, Partanen J, Ukkonen E, Taipale J. 2006. Genome-wide prediction of mammalian enhancers based on analysis of transcriptionfactor binding affinity. Cell 124: 47-59.

Han MH, Hwang SI, Roy DB, Lundgren DH, Price JV, Ousman SS, Fernald GH, Gerlitz B, Robinson WH, Baranzini SE, et al. 2008. Proteomic analysis of active multiple sclerosis lesions reveals therapeutic targets. Nature 451: 10761081.

Harada N, Oshima H, Katoh M, Tamai Y, Oshima M, Taketo MM. 1999. Intestinal polyposis in mice with a dominant stable mutation of the $\beta$-catenin gene. EMBO J 18: 59315942.

He Y, Dupree J, Wang J, Sandoval J, Li J, Liu H, Shi Y, Nave KA, Cassacia-Bonnefil P. 2007. The transcription factor Yin Yang 1 is essential for oligodendrocyte progenitor differentiation. Neuron 55: 217-230.

John GR, Shankar SL, Shafit-Zagardo B, Massimi A, Lee SC, Raine CS, Brosnan CF. 2002. Multiple sclerosis: Re-expression of a developmental pathway that restricts oligodendrocyte maturation. Nat Med 8: 1115-1121.

Kawasoe T, Furukawa Y, Daigo Y, Nishiwaki T, Ishiguro $H$, Fujita M, Satoh S, Miwa N, Nagasawa Y, Miyoshi Y, et al. 2000. Isolation and characterization of a novel human gene, DRCTNNB1A, the expression of which is down-regulated by $\beta$-catenin. Cancer Res 60: 3354-3358.

Kessaris N, Fogarty M, Iannarelli P, Grist M, Wegner M, Richardson WD. 2006. Competing waves of oligodendrocytes in the forebrain and postnatal elimination of an embryonic lineage. Nat Neurosci 9: 173-179.

Kim S, Kim SH, Kim H, Chung AY, Cha YI, Kim CH, Huh TL, Park HC. 2008. Frizzled 8a function is required for oligoden- drocyte development in the zebrafish spinal cord. Dev Dyn 237: 3324-3331.

Kitada M, Rowitch DH. 2006. Transcription factor co-expression patterns indicate heterogeneity of oligodendroglial subpopulationsin adult spinal cord. Glia 54: 35-46.

Kotter MR, Li W-W, Chao Z, Franklin RJM. 2006. Myelin impairs CNS remyelination by inhibiting oligodendrocyte precursor cell differentiation. I Neurosci 26: 328-332.

Kuhlmann T, Miron V, Cuo Q, Wegner C, Antel J, Brück W. 2008. Differentiation block of oligodendroglial progenitor cells as a cause for remyelination failure in chronic multiple sclerosis. Brain 131: 1749-1758.

Lei Q, Jeong Y, Misra K, Li S, Zelman AK, Epstein DJ, Matise MP. 2006. Wnt signaling inhibitors regulate the transcriptional response to morphogenetic Shh-Gli signaling in the neural tube. Dev Cell 11: 325-337.

Ligon KL, Alberta JA, Kho AT, Weiss J, Kwaan MR, Nutt CL, Louis DN, Stiles CD, Rowitch DH. 2004. The oligodendroglial lineage marker OLIG2 is universally expressed in diffuse gliomas. J Neuropathol Exp Neurol 63: 499-509.

Lock C, Hermans G, Pedotti R, Brendolan A, Schadt E, Garren H, Langer-Gould A, Strober S, Cannella B, Allard J, et al. 2002. Gene-microarray analysis of multiple sclerosis lesions yields new targets validated in autoimmune encephalomyelitis. Nat Med 8: 500-508.

Lustig B, Jerchow B, Sachs M, Weiler S, Pietsch T, Karsten U, van de Wetering $M$, Clevers $H$, Schlag PM, Birchmeier W, et al. 2002. Negative feedback loop of Wnt signalling through upregulation of conductin/axin2 in colorectal and liver tumors. Mol Cell Biol 22: 1184-1193.

Maretto S, Cordenonsi M, Dupont S, Braghetta P, Broccoli V, Hassan AB, Volpin D, Bressan GM, Piccolo S. 2003. Mapping Wnt $/ \beta$-catenin signaling during mouse development and in colorectal tumors. Proc Nat1 Acad Sci 100: 3299-3304.

Mi S, Miller RH, Lee X, Scott ML, Shulag-Morskaya S, Shao Z, Chang J, Thill G, Levesque M, Zhang M, et al. 2005. LINGO-1 negatively regulates myelination by oligodendrocytes. Nat Neurosci 8: 745-751.

Miller RH. 2002. Regulation of oligodendrocyte development in the vertebrate CNS. Prog Neurobiol 67: 451-467.

Miller RH, Mi S. 2007. Dissecting demyelination. Nat Neurosci 10: 1351-1354.

Nelson WJ, Nusse R. 2004. Convergence of Wnt, $\beta$-catenin, and cadherin pathways. Science 303: 1483-1487.

Patani R, Vora A, Reynolds R. 2007. Remyelination can be extensive in multiple sclerosis despite a long disease course. Neuropathol Appl Neurobiol 33: 277-287.

Patrikios P, Stadelmann C, Kutzelnigg A, Rauschka H, Schmidbauer M, Laursen $H$, Sorensen PS, Brück W, Lucchinetti C, Lassmann H. 2006. Remyelination is extensive in a subset of multiple sclerosis patients. Brain 129: 3165-3172.

Schüller U, Heine VM, Mao J, Kho AT, Dillon AK, Han YG, Huillard E, Sun T, Ligon AH, Qian Y, et al. 2008. Acquisition of granule neuron precursor identity is a critical determinant of progenitor cell competence to form Hedgehog-induced medulloblastoma. Cancer Cell 14: 123-134.

Shen S, Sandoval J, Swiss VA, Li J, Dupree J, Franklin RJM, Casaccia-Bonnefil P. 2008. Age-dependent epigenetic control of differentiation inhibitors is critical for remyelination efficiency. Nat Neurosci 11: 1024-1034.

Shimizu T, Kagawa T, Wada T, Muroyama Y, Takada S, Ikenaka K. 2005. Wnt signaling controls the timing of oligodendrocyte development in the spinal cord. Dev Biol 282: 397-410.

Su LK, Kinzler KW, Vogelstein B, Preisinger AC, Moser AR, Luongo C, Gould KA, Dove WF. 1992. Multiple intestinal 
neoplasia caused by a mutation in the murine homolog of the APC gene. Science 256: 668-670.

Trapp BD, Nave KA. 2008. Multiple sclerosis: An immune or neurodegenerative disorder? Annu Rev Neurosci 31: 247269.

Vallstedt A, Klos JM, Ericson J. 2005. Multiple dorsoventral origins of oligodendrocyte generation in the spinal cord and hindbrain. Neuron 45: 55-67.

van de Wetering M, Sancho E, Verweij C, de Lau W, Oving I, Hurlstone A, van der Horn K, Batlle E, Coudreuse D, Haramis AP, et al. 2002. The $\beta$-catenin/TCF-4 complex imposes a crypt progenitor phenotype on colorectal cancer cells. Cell 111: 241-250.

Wolswijk G. 1998. Chronic stage multiple sclerosis lesions contain a relatively quiescent population of oligodendrocyte precursor cells. J Neurosci 18: 601-609.

Yang L, Lin C, Liu ZR. 2006. P68 RNA helicase mediates PDGFinduced epithelial mesenchymal transition by displacing Axin from $\beta$-catenin. Cell 127: 139-155.

Zara F, Biancheri R, Bruno C, Bordo L, Assereto S, Gazzerro E, Sotgia F, Wang XB, Gianotti S, Stringara S, et al. 2006. Deficiency of hyccin, a newly identified membrane protein, causes hypomyelination and congenital cataract. Nat Genet 38: 1111-1113. 


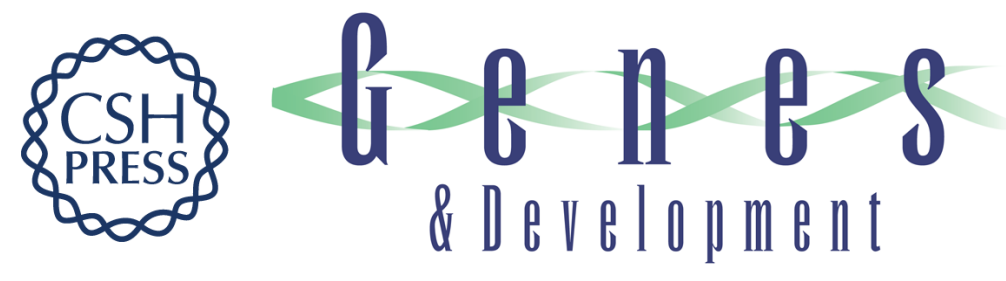

\title{
Dysregulation of the Wnt pathway inhibits timely myelination and remyelination in the mammalian CNS
}

\author{
Stephen P.J. Fancy, Sergio E. Baranzini, Chao Zhao, et al.
}

Genes Dev. 2009, 23: originally published online June 10, 2009

Access the most recent version at doi:10.1101/gad.1806309

\section{Supplemental http://genesdev.cshlp.org/content/suppl/2009/06/11/gad.1806309.DC1 \\ Material}

Related Content Modulating myelination: knowing when to say Wnt

Sheila S. Rosenberg and Jonah R. Chan

Genes Dev. July, 2009 23: 1487-1493

References This article cites 48 articles, 13 of which can be accessed free at:

http://genesdev.cshlp.org/content/23/13/1571.full.html\#ref-list-1

Articles cited in:

http://genesdev.cshlp.org/content/23/13/1571.full.html\#related-urls

License Freely available online through the Genes \& Development Open Access option.

Email Alerting Receive free email alerts when new articles cite this article - sign up in the box at the top Service right corner of the article or click here.

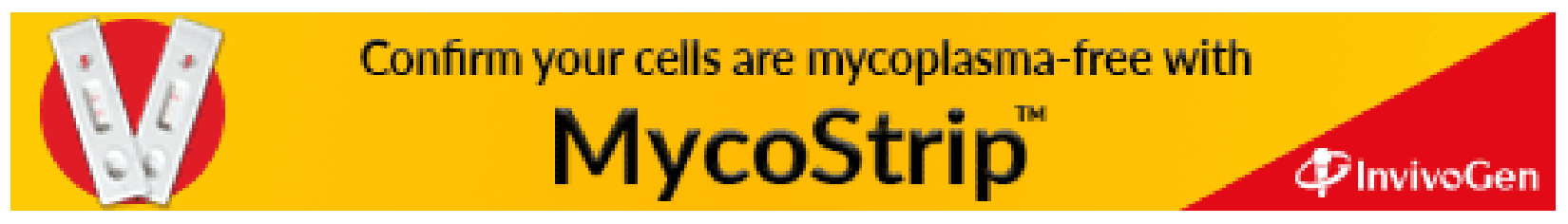

